\title{
The costs of vilifying pharma
}

\section{Part II of a series on conflicts of interest in medicine (Part 1)}

$\mathrm{T}$ he practice of medicine is more transparent today than it was even a decade ago. Clinical trial registration, disclosure of physician-industry relationships at continuing medical education events, the Physician Payments Sunshine Act in the United States these and other efforts have shed light on conflicts of interest and exposed potential biases. Though many transparency advocates say even more should be done, some doctors aren't so sure.

There is concern in some corners that the quest to ferret out conflicts of interest in medical research has become overzealous, that it has morphed into a religious-like crusade based more on morality than evidence of harm. Nobody denies there are risks when medical research is funded by the pharmaceutical industry. And it is well known that some drug companies have withheld clinical data, misrepresented research, promoted off-label use of their products or misbehaved in other ways.

Still, the overemphasis on highlighting the risks of physicians working with drug companies may be tainting any form of collaboration with the pharmaceutical industry, warn some doctors. They are worried this will discourage academic researchers from working on new therapies, slow innovation in medicine and cause good data to be ignored. It is one thing to be cautious, they suggest, and quite another to be a complete cynic.

"Any kind of relationship with industry is automatically viewed with great suspicion and that can be counterproductive," said Dr. Michel Accad, a cardiologist and internist in San Francisco who criticized the "religious fervour" against conflicts of interest on his website Alert and Oriented. "Frequently, scientific results are interpreted negatively just on the basis of a tie between a physician-scientist and industry as opposed to analyzing what the data actually shows."

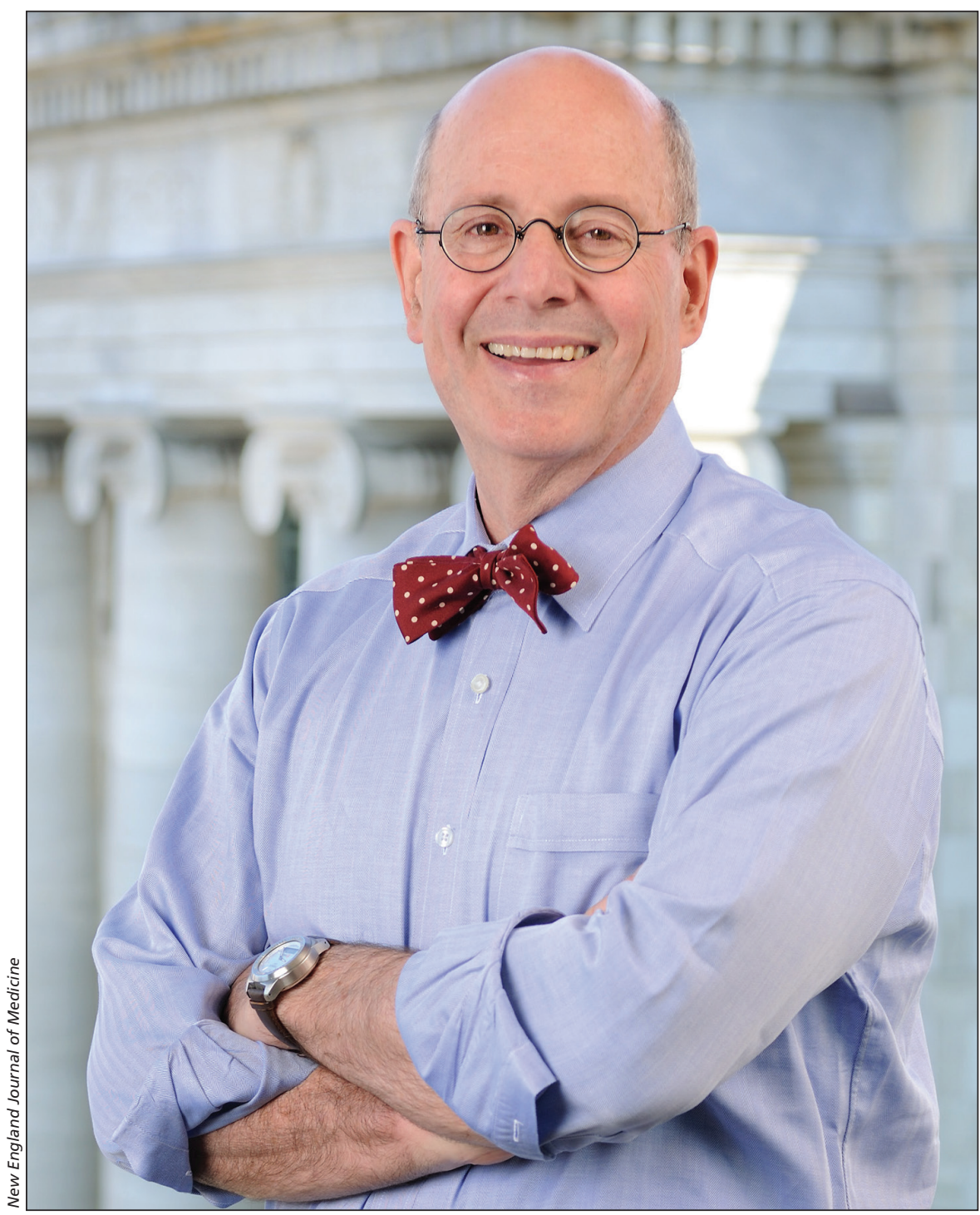

An anti-pharma bias may be steering bright young doctors away from areas of medicine in need of innovation, worries Dr. Jeffrey Drazen, editor-in-chief of the New England Journal of Medicine.

According to Dr. Jeffrey Drazen, editor-in-chief of the New England Journal of Medicine, many physicians are picking up an anti-pharma bias early in their careers or even in medical school. So they may steer clear of pursuing research in emerging diseases or other areas lacking effective drugs for fear of being labelled sellouts. "Are we taking the best and brightest people and scaring them away from a career where they can make a difference because we are branding that work as unsuitable for a high-minded person?" said Drazen.

Medical publishing has also been affected, especially for papers on new drugs. To eliminate the risk of bias, a journal could insist that the authors of articles offering guidance on the use of a drug have no relationships with the company that made it. Unfortunately, that would rule out all researchers who participated in the clinical trial. That is why decisions about publishing authors 
with industry ties should be made on a case-by-case basis, said Drazen. You have to consider all the circumstances and balance the risk of bias with the reward of better information.

"If you want someone who really knows a lot about a new drug, they would have to had participated in the trial and therefore they would have to had worked with a drug company, because they are the people doing the trials," said Drazen. "On the other hand, if you want someone with absolutely no interaction with the company, then you get someone who doesn't really have that deep knowledge, so they can't speak with the same authority."

Vilifying the medical-products industry will also discourage academic physicians from focusing on research that can make an actual difference in the lives of patients, according to Dr. Thomas Stossel, director of translational medicine at Brigham and Women's Hospital in Boston. Stossel first became aware of what he has called "conflict-of-interest mania" in 1987, after joining the scientific advi- sory board of a biotech company called Biogen.

"Most researchers don't care about innovation. They care about impressing each other. I'm a lifer and I play that game very well, but nobody lived one minute longer because of my success," said Stossel. "My experience with Biogen enabled me to branch off and work on some projects that may save lives, even if they had a $90 \%$ chance of failing."

Yes, there will be a few bad actors in the medical-products industry, as there are in any industry, acknowledged Stossel. But it is best to address problems as they arise, he said, rather than devote enormous resources to preventing them from happening. "We have this vast array of prophylactic management," said Stossel. "It has slowed down innovation and will continue to do so."

Another area where conflicts of interest are evaluated more closely than ever is in the formation of committees to produce clinical practice guidelines. Again, as in medical publishing, there is disagreement about the importance of eliminating bias versus attracting expertise.

"I come down on the side that keeping people who have done clinical trials and worked with industry off guideline committees is silly. Some other people say that is ridiculous and you can always find someone without industry ties. Of course you can find someone. But are you finding the most expert someone?" said Dr. Lisa Rosenbaum, a cardiologist and national correspondent for the New England Journal of Medicine. "If we turn not working with industry into a marketable virtue, that is itself an issue."

Rosenbaum recently wrote a threepart series that re-examined the tradeoffs in regulating conflicts of interest in medicine. If the polarized online reaction to those articles is any indication, starting a fresh conversation on physicians-industry relations is no easy task. - Roger Collier, CMAJ

Next: Part III: Pharmaphobes, pharamascolds and conflict denialists

CMAJ 2015. DOI:10.1503/cmaj.109-5112 